\title{
A Probabilistic Rain Diagnostic Model Based on Cyclone Statistical Analysis
}

\author{
V. Iordanidou, ${ }^{1}$ A. G. Koutroulis, ${ }^{1}$ and I. K. Tsanis ${ }^{1,2}$ \\ ${ }^{1}$ Department of Environmental Engineering, Technical University of Crete, 73100 Chania, Greece \\ ${ }^{2}$ Department of Civil Engineering, McMaster University, Hamilton, ON, Canada L8S 4 L7
}

Correspondence should be addressed to I. K. Tsanis; tsanis@hydromech.gr

Received 13 March 2014; Accepted 23 May 2014; Published 11 June 2014

Academic Editor: Hiroyuki Hashiguchi

Copyright (C) 2014 V. Iordanidou et al. This is an open access article distributed under the Creative Commons Attribution License, which permits unrestricted use, distribution, and reproduction in any medium, provided the original work is properly cited.

\begin{abstract}
Data from a dense network of 69 daily precipitation gauges over the island of Crete and cyclone climatological analysis over middleeastern Mediterranean are combined in a statistical approach to develop a rain diagnostic model. Regarding the dataset, $0.5 \times$ 0.5, 33-year (1979-2011) European Centre for Medium-Range Weather Forecasts (ECMWF) reanalysis (ERA-Interim) is used. The cyclone tracks and their characteristics are identified with the aid of Melbourne University algorithm (MS scheme). The region of interest is divided into a grid mesh and for each grid the probability of rain occurrence from passing cyclones is estimated. Such probability maps are estimated for three rain intensity categories. The probability maps are evaluated for random partitions of the data as well as for selected rain periods. Cyclones passing south of Italy are found to have greater probability of producing light rain events in Crete in contrast to medium and heavy rain events which are mostly triggered by cyclones of southern trajectories. The performance of the probability maps is very satisfactory, recognizing the majority of "affecting" cyclones and rejecting most cyclones that do not trigger rain events. Statistical measures of sensitivity and specificity range between 0.5 and 0.8 resulting in effective forecasting potential.
\end{abstract}

\section{Introduction}

The growth of popularity, tourism, and industry in the Mediterranean region increases its sensitivity to the impact of natural disasters such as floods and landslides $[1,2]$. In addition, the complex topography of the Mediterranean region characterized by its orography and coastlines is vulnerable to cyclone formation or "cyclogenesis" [3-5]. Cyclones and rainfall are strongly associated $[1,6]$ especially in the Mediterranean where they have a great contribution in organizing the low-level flow and moisture and as such feeding the precipitation systems $[2,7]$.

It has been subject of numerous researchers to analyze the relationship of rain with cyclones in the Mediterranean region. The majority of studies agree that cyclones' attributes and frequency influence precipitation regime. Both Hawcroft et al. [8] and Catto et al. [9] agree that most of the total precipitation in the northern hemisphere is triggered by extratropical cyclones. The same verification holds for the south hemisphere according to Papritz et al. [10] who found that $60 \%-90 \%$ of "strong" precipitation is triggered by those systems. Extreme rainfall is also connected with cyclonic circulation patterns. Jansa et al. [11] found that heavy rain events ( $>60 \mathrm{~mm} /$ day) gauged in different Mediterranean sites are associated with cyclones' appearance in the wider area. In addition, Reale and Lionello [2] observed that there is a higher probability to detect a cyclone within a distance of $20^{\circ}$ (about $2000 \mathrm{~km}$ ) for intense precipitation events at 15 Mediterranean coastal locations. The Mediterranean rainfall decrease especially during the winter is found to be related with cyclones' frequency decline [12]. Changes in cyclonic circulation patterns also are responsible for precipitation amount and occurrence according to an analysis over the Greek territory [13]. In addition, regarding future climate scenarios, changes of precipitation are consistent with changes in cyclonic activity $[5,14]$. 


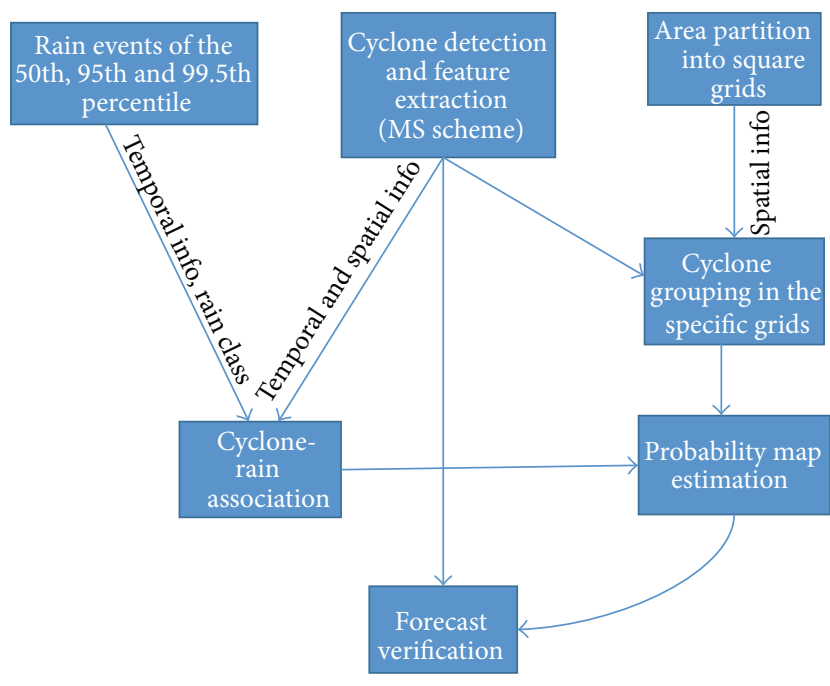

FIgURE 1: Analysis procedure diagram.

Many algorithms and software packages have been developed for the identification of the cyclones and their tracking. The intercomparison of midlatitude storm diagnostics (IMILAST) team has evaluated 15 different algorithms of cyclone identification and tracking for the same dataset and found inconsistencies among the schemes for both reanalysis (ERAInterim) and model simulations (ECHAM5/OM1) concerning variables such as the number of identified cyclones, cyclone frequency, and life cycle $[15,16]$.

Being an important driver for precipitation, cyclones have been thoroughly investigated with respect to their lifetime, frequency, evolution, and origin. Campins et al. [7] investigated the climatology of Mediterranean cyclones for a 45-year period (1957-2002) pointing out the gulf of Genoa and Cyprus as two important cyclogenetic regions along with regions in North Africa, the Iberian peninsula, the Aegean sea, and the Algerian sea. In this study seasonal variabilities are identified in agreement with other studies $[4,17-21]$ noting significant difference in cyclones' frequency. In both Nissen et al. [22] and Flocas et al. [19] a negative trend in western cyclonic systems is identified in contrast to eastern Mediterranean where a small increase can be observed. With regards to cyclone development, Rudeva and Gulev [23] found that for cyclones of the northern hemisphere over the period 1948-2004, cyclone size (radius) is a crucial parameter affecting cyclone lifetime and intensity. In this direction with the aid of MS scheme Simmonds [24] shows how the cyclone radius grows through the life of a cyclone.

Motivated from the fact that precipitation is closely related to cyclone presence and that a great effort has been made for the proper comprehension of the cyclonic systems, this work suggests a simple probabilistic model based on the statistical analysis of cyclones, for rain prediction. Our methodology is based on the estimation of probabilities on a gridded area of analysis concerning the cyclone passages and their association to recorded rain events. The estimated so-called "probability maps" are then used as drivers to give a prediction for a potential rain event. The verification procedures used here are the measures of sensitivity (referred to as probability of detection in other studies), specificity (also referred as false alarm ratio), and accuracy $[25,26]$. The proposed methodology is evaluated on middle-eastern Mediterranean region for the rain events of the island of Crete, Greece.

\section{Data and Methodology}

The main objective of this work is the estimation of spatial probability maps of cyclones responsible for rain events. In addition, a statistical approach is evaluated for rain events forecasting. The statistical analysis is extended including conditional cyclones characteristics such as cyclone intensity, depth, and radius. Figure 1 presents a brief diagrammatic overview of the procedure. In a nutshell, during the first step of the analysis three independent procedures take place. (a) Rain categories are selected according to specific percentiles (depending on the application, 50th, 95th, and 99.5th in our case), (b) cyclones and their characteristics are recognized with a selected algorithm (MS scheme in this work), and (c) the selected area of interest is partitioned in grid cells of preferred resolution $(0.5 \times 0.5 \mathrm{deg}$. of lat. here). Temporal and spatial information of the cyclones and the area partition are evaluated for the cyclones' grouping and rain-cyclone features are examined to associate the two physical processes. The probability values are computed for each grid cell according to the rain-cyclone association leading to the formation of the respective probability maps. The final step of the analysis concerns rain forecast verification using the cyclone statistics of the probability maps and the original cyclone data.

2.1. Data. In the present analysis we use the European Centre for Medium-Range Weather Forecasts (ECMWF) ERA-Interim reanalysis dataset for the period between 1979 and 2011. The ERA-Interim data are of 6-hour temporal resolution at base times 0000, 0600, 1200, and 1800 UTC and have a regular latitude-longitude with a spatial resolution of $0.5^{\circ} \times 0.5^{\circ}$. The field of mean sea-level pressure (MSLP) is analyzed for the identification of the cyclones' positions and parameters as well as their tracks. Investigated are autumn, winter, and spring covering the months from September to May. Summer period is excluded from the analysis as there is negligible rainfall over Crete. The cyclones are treated as a whole in time and not seasonally grouped which is expected to be investigated in our subsequent work. Seasonality consideration is expected to lead to different results regarding to the fact that the majority of rain events in Crete occur during winter. The domain of study for the detection and identification of the cyclones includes part of the middleeastern Mediterranean area and extends between $4^{\circ}-33^{\circ} \mathrm{E}$ and $32^{\circ}-43^{\circ} \mathrm{N}$.

The area of interest according to the rain events is Crete which is enclosed within the domain of $23.4^{\circ}-26.4^{\circ} \mathrm{E}$ and $34.8^{\circ}-35.7^{\circ} \mathrm{N}$. The domain of study and Crete boundary are shown in Figure 2. Precipitation records in Crete were obtained for 69 daily gauging stations, compiled and quality controlled by the Directorate of Water of the Decentralized 


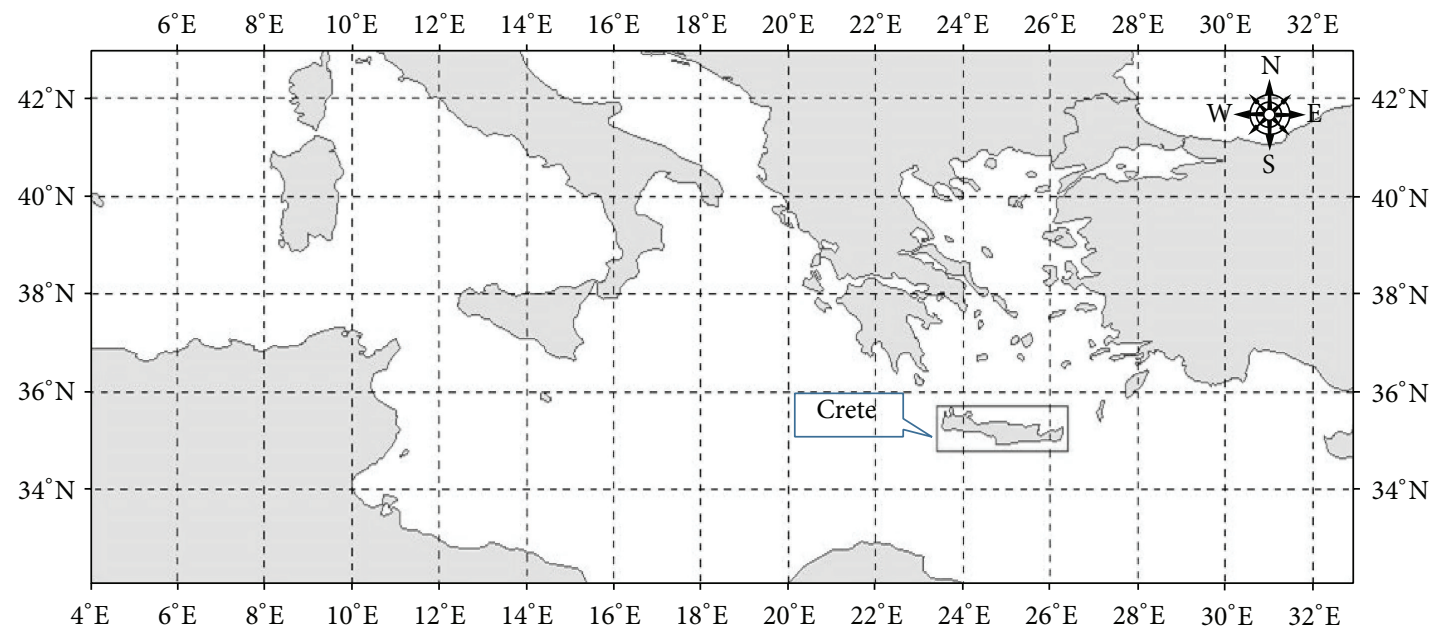

Figure 2: The domain of study including part of middle-eastern Mediterranean. Noted is Crete for which rain events are investigated.

Administration of Crete. Flood events affecting Crete are also investigated, selected from several flood events databases (http://ceogis-floods.web.auth.gr/) for which more information can be found in [27-29].

2.2. Cyclone Tracking. Cyclones are detected using the Melbourne University finding and tracking scheme (from now on referred to as MS scheme) based on the quasi-Lagrangian perspective [30, 31]. MS scheme works with PMSL fields projected on a polar stereographic grid with the aid of bicubic splines. The identification of possible search areas is achieved by looking for maxima of the pressure gradient, an approach similar to vorticity maxima identification. Thereafter, pressure minima are identified in the selected areas. This strategy gives the advantage of finding both close and open cyclones which is of great importance because cyclones develop during their life cycle. Hence, missing open lows could lead to time series break of a cyclone system. Hope et al. [32] developed a frontal analysis scheme based on MS scheme for the better identification of open cyclone-precipitation association due to the fact that open depressions' identification is of great importance as they are usually associated with rainfall.

Cyclone radius, depth, and intensity are retrieved from MS scheme and are calculated according to the following formulas.

Cyclone radius is estimated as

$$
R^{2}=\frac{1}{N} \sum_{i=1}^{N} r_{i}^{2},
$$

where $r_{i}$ is the distance of the radial line from the cyclone center to the points at which the Laplacian of the pressure is zero. $N$ concerns the number of the radial lines drawn for every $20^{\circ}[30,33]$.

The Laplacian of the central pressure $\nabla^{2} P$ appropriately describes cyclone intensity $[30,33,34]$. Cyclone depth $D$ is a measure proportional of pressure gradient and radius given by

$$
D=\frac{1}{4} R^{2} \nabla^{2} P
$$

2.3. Cyclone-Rain Association. The cyclones identified with the aid of MS scheme need to be associated with specific rain events in the region of interest. Cyclone-rain association is achieved with temporal and spatial information analysis of cyclone and rain records.

Two definitions of cyclones state were adopted in terms of their temporal evolution over the domain of the study. From this point on, "hitting" cyclones are defined as the cyclones at a specific time-point of their track that at the same time are responsible for rain occurrence over Crete. Thus, "hitting" cyclones have both temporal and spatial relation with the recorded rain event, as follows in the description. The second definition characterizes the cyclones that within the track evolution at some subsequent point will affect the area of interest by producing rain and will be referred to as "affecting" cyclones. If a cyclone is characterized as "hitting" (rain producing) at some point within its track, then at its previous points the same cyclone is an "affecting" cyclone, which will eventually trigger a rain event over Crete.

Temporally, cyclone characteristics (like center) are estimated every 6 hours while rain records are daily. Hence, the cyclones between two successive rain recordings are those that potentially trigger the second rain event. According to the 50th, 95th, and 99.5th percentiles of daily rainfall accumulation, rain events are divided in three rain categories of light, medium, and heavy rain, corresponding to 8.5, 47.3, and $106 \mathrm{~mm} /$ day, respectively. The rain thresholds used in this study are 10,50, and $100 \mathrm{~mm} /$ day in terms of simplicity, which approximately correspond to the exact values and occur after "dry" records of less than $1 \mathrm{~mm}$ /day are excluded from the analysis. A rain event is defined when rainfall of more than $1 \mathrm{~mm}$ is recorded for at least one of the 69 stations of Crete. 
Another important aspect of rainfall-cyclone association is the cyclone center location in relation to the area of interest (Crete). The "sufficient affecting" distance between the cyclone center and this region should be less than the cyclone's radius. A rectangular boundary (Figure 2) enclosing the area of interest is defined and Euclidian distance between the cyclone center and the boundary is estimated and compared to cyclone radius in order to define the specific cyclone as "hitting," and thus practically associated with the recorded rain event over Crete. More complex distance measures are not considered due to inconsistencies of the tracking scheme with regards to the cyclone center location and its radius. Also, distance is not measured directly from the cyclone center to the exact gauging station because cyclone structure is not an exact circle so considering the exact distance could lead to loss of information.

2.4. Spatial Probability Maps. In order to estimate the probability of a cyclone detected within middle-eastern Mediterranean area to trigger rain events in the area of Crete we use a $0.5 \times 0.5$ grid mesh. Passing cyclones are assigned to each grid according to their center coordinates (longitude-latitude values compared to the grid's boundaries). Probabilities concern the number of cyclones affecting Crete to the total number of cyclones and are estimated for every cell according to

$$
\operatorname{Pr}_{c, \mathrm{rc}}=\frac{\mathrm{AC}_{c, \mathrm{rc}}}{\mathrm{TC}_{c, \mathrm{rc}}}
$$

where $\operatorname{Pr}_{c, \text { rc }}$ is the probability of a cyclone passing over cell $c$ to affect the area of interest with a rc rain category event. AC corresponds to the number of affecting cyclones and TC to the total number of cyclones. Both of these are estimated for every grid and for every rain category.

Another probability measure applied is that of weightednormalized probability (WNP) which is estimated by multiplying $\operatorname{Pr}_{c, \text { rc }}$ with the number of cyclones $C$. The result is then normalized to range between 0 and 1 over the total number of cells for each rain category:

$$
\mathrm{WNP}_{c, \mathrm{rc}}=\frac{\operatorname{Pr}_{c, \mathrm{rc}} * C_{c, \mathrm{rc}}}{\max _{c}\left(\operatorname{Pr}_{c, \mathrm{rc}} * C_{c, \mathrm{rc}}\right)}
$$

In addition probability maps are estimated for cyclones having extreme characteristics. The characteristics of depth, intensity, and radius are constrained to be greater than their mean value plus two times their variance which corresponds to $2.3 \%$ of the data, considering normal distribution, and even less in distributions of positive skew.

2.5. Forecast Verification. Spatial probability maps are tested with statistical measures of sensitivity, specificity, and accuracy which show the performance of cyclone matching to the rain events. 10 -fold cross-validation combined with 100 Monte Carlo simulation results in 1000 different test and train datasets for this testing. More specifically, with 10-fold crossvalidation the dataset is randomly grouped in 10 different classes consisting of full cyclone tracks. These 10 experimental
TABLE 1: Types of probability maps.

\begin{tabular}{ll}
\hline "NoCri": & Simple probability maps (no extra criteria). \\
\hline "3Cri": & $\begin{array}{l}\text { Simple probability maps complementary to } \\
\text { constrained probability maps on depth, radius, } \\
\text { and intensity (criteria on cyclone selection). }\end{array}$ \\
\hline "WN": & WNP maps. \\
\hline "WN3Cri": & $\begin{array}{l}\text { WNP maps complementary to WNP constrained } \\
\text { probability maps on depth, radius, and intensity. }\end{array}$ \\
\hline "NoCri + WN": & $\begin{array}{l}\text { Simple probability maps complementary to WNP } \\
\text { maps. }\end{array}$ \\
\hline
\end{tabular}

datasets correspond to 10 experiments that for each one of the classes is used as a test dataset and the remaining 9 as a train dataset. The procedure is repeated 100 times in terms of the well-known Monte Carlo simulation.

The criterion for a cyclone to be considered as "affecting" depends on a probability threshold. If the cyclone center is located in a grid cell whose estimated probability (in the probability map) is higher than the defined threshold, then the cyclone is considered to be an "affecting" cyclone. The threshold is optimized to give the higher values to the three statistical measures of sensitivity, specificity, and accuracy. When more than one probability maps are taken into account to decide the effectiveness of a cyclone, each map has a positive impact on the decision of whether the cyclone affects Crete or not; in other words each map gives a positive "vote." More specifically, if at least one of the maps gives a probability value over the defined threshold (positive vote) then the decision is that the cyclone is an "affective" cyclone that will eventually "hit" Crete. Five different probability maps (simple or combinations) are investigated (Table 1).

Once a cyclone at a specific point of the track is found to be affective according to the estimated probability maps, this track is considered as an affecting pathway that will eventually "hit" Crete. According to whether this decision is true or false, the statistical measures of sensitivity, specificity, and accuracy are estimated, constituting well-known verification procedures $[25,26]$.

The following terms need to be defined in order to present sensitivity, specificity, and accuracy (Table 2).

Sensitivity measure is given by

$$
S=\frac{\mathrm{TP}}{\mathrm{P}}=\frac{\mathrm{TP}}{\mathrm{TP}+\mathrm{FN}}
$$

where sensitivity $S$ is the ratio of true positives to all the real positive values, recognized or not as positive. Sensitivity indicates the cyclone probability map's ability to identify rain events. The higher the sensitivity the more cyclones causing rain events are identified.

The formula describing specificity is given by

$$
\mathrm{SP}=\frac{\mathrm{TN}}{\mathrm{N}}=\frac{\mathrm{TN}}{\mathrm{TN}+\mathrm{FP}}
$$

where specificity SP is the ratio of true negatives to all the real negative values, recognized or not as negative. Specificity indicates the cyclone probability map's ability to correctly 
TABLE 2: Sensitivity, specificity, and accuracy definition terms.

\begin{tabular}{ll}
\hline True Positive (TP): & $\begin{array}{l}\text { The cyclone produces rain and the test is } \\
\text { positive. }\end{array}$ \\
\hline False Positive (FP): & $\begin{array}{l}\text { The cyclone does not produce rain but the } \\
\text { test is positive. }\end{array}$ \\
\hline True Negative (TN): & $\begin{array}{l}\text { The cyclone does not produce rain and the } \\
\text { test is negative. }\end{array}$ \\
\hline False Negative (FN): & $\begin{array}{l}\text { The cyclone does produce rain but the test is } \\
\text { negative. }\end{array}$ \\
\hline Positive $(\mathrm{P}):$ & Sum of TP and FN. \\
\hline Negative $(\mathrm{N}):$ & Sum of TN and FP. \\
\hline
\end{tabular}

reject the hypothesis that a cyclone causes a rain event. The higher the specificity the more cyclones not causing rain events are identified.

Lastly, accuracy is given by

$$
\mathrm{AC}=\frac{\mathrm{TP}+\mathrm{TN}}{\mathrm{P}+\mathrm{N}}=\frac{\mathrm{TP}+\mathrm{TN}}{\mathrm{TN}+\mathrm{TN}+\mathrm{FP}+\mathrm{FN}} .
$$

So accuracy AC is the ratio of the correct positive and negative choices made from the cyclone probability map to the whole cyclone population.

\section{Results/Discussion}

3.1. Distribution of Affecting and Hitting Cyclones. The combined number of "hitting" and "affecting" cyclones for the 1979-2011 period is presented in Figure 3. For light rain events the majority of responsible cyclones are located over north Levantine Basin (east of Crete), over the Aegean Sea (north), and over Ionian Sea (northwest) of Crete. For medium and heavy rain events, the related cyclonic activity is found further south. Cyclones causing medium rain are primarily located east of Crete. This is less marked for heavy rain, where cyclones seem to be uniformly distributed around Crete. The number of identified affecting and hitting cyclones are in agreement with the findings of Kouroutzoglou et al., [35] regarding the frequency of explosive events developed in eastern Mediterranean, who also found that that almost 55\% of the events occur during winter and no cases in summer, supporting our exclusion of summer period. Obviously, the number of cyclones gets smaller for rain events of greater accumulation, as the majority of rain events are of light rain category (50th-95th percentile) and very few are in medium rain category $(99,5$ th percentile).

The probability of a "hitting" cyclone as well as WNP measure for the 1979-2011 period is illustrated in Figure 4. The probability of a passing cyclone to "hit" Crete is higher when passing south of Crete, which gets more profound for greater rain accumulation. On the other hand, the corresponding weighted probability emphasizes regions east of Crete as "hitting" hotspots. Again here hotspots are moved south of Crete for greater rain accumulations.

The corresponding results for "affecting" cyclones for the same period are presented in Figure 5. As it is expected, "affecting" cyclones are in bigger distance than the "hitting"

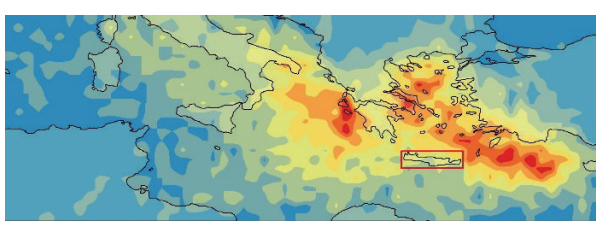

(A1)

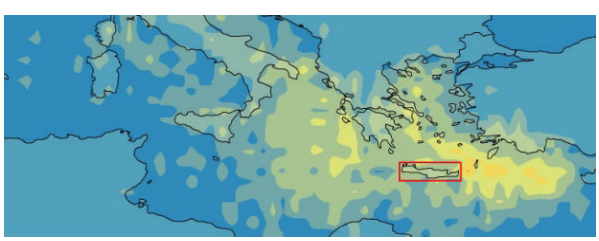

(A2)

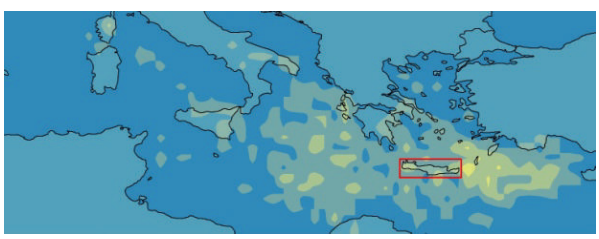

(A3)

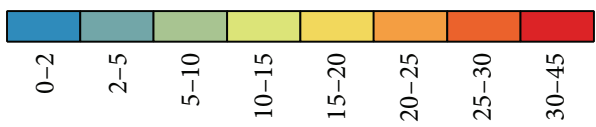

FIGURE 3: Number of "affecting" and "hitting" cyclones for the time period 1979-2011 for (1) light, (2) medium, and (3) heavy rain events.

cyclones. Cyclones passing south of Italy have greater probability of affecting Crete. The "affecting" cyclones' pathways are concentrated southerly, over western Ionian Basin, for medium and especially heavy rain events. For WNP measure, hotspots can be distinguished on the maps as more "location specific" areas. The western Ionian Sea region south of Italy stands out for light rain as an important hotspot, as both the cyclone probability to affect Crete and the number of cyclones (Figure 2) are high in this case. For both medium and heavy rain, hotspots are shifted south and the weighted probabilities are lower compared to the ones of the light rain events. These high probabilities located at the boundaries between central and eastern Mediterranean are in correspondence with the findings of Kouroutzoglou et al. [36] that the upper levels $(500 \mathrm{hPa})$ maximum intensity and size of the explosive cyclones and the maximum geostrophic vorticity at $500 \mathrm{hPa}$ in the Mediterranean are formed at the same area.

Figure 6 illustrates the estimated probability maps for "affecting" cyclones constrained on the extreme values (upper tails) of their depth, radius, and intensity. The regions where "affecting" cyclones have higher probabilities are distributed relevant to those of Figure 5. Probabilities in this case are higher suggesting that cyclones with extreme characteristics are more likely to affect Crete. For light rain a robust pattern of affecting cyclone activity is observed in the wider southern Italy region for all cyclone characteristics' constrains. Heavy rain events are associated with extreme cyclones passing over south Ionian Basin, a finding in great correspondence with the results of Kouroutzoglou et al. [36] that the greater depth 


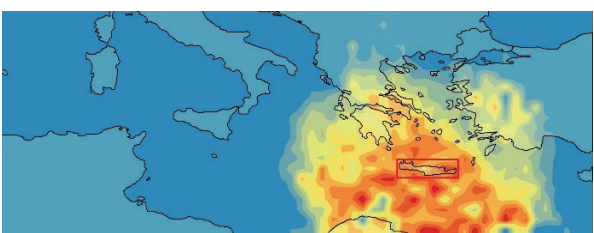

(A1)

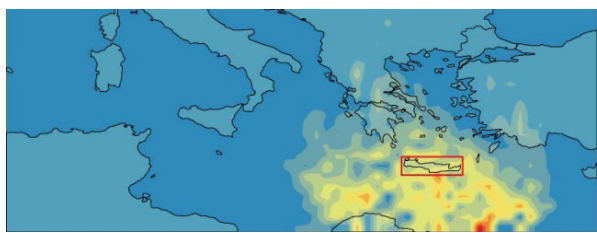

(A2)

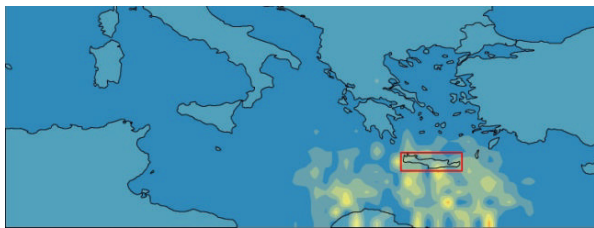

(A3)

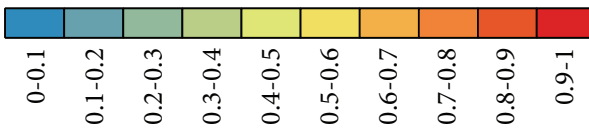

(a)

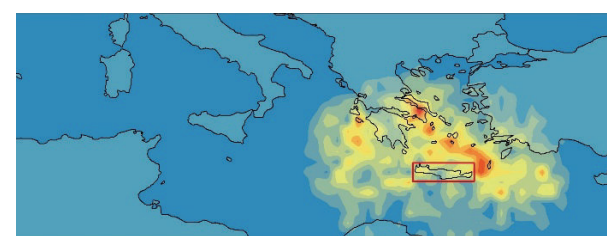

(B1)

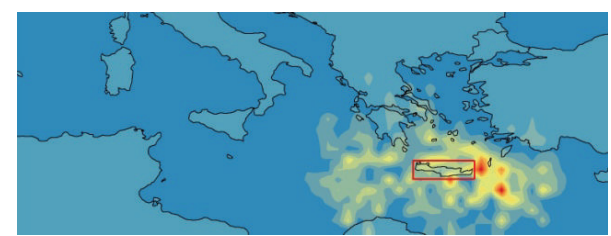

(B2)

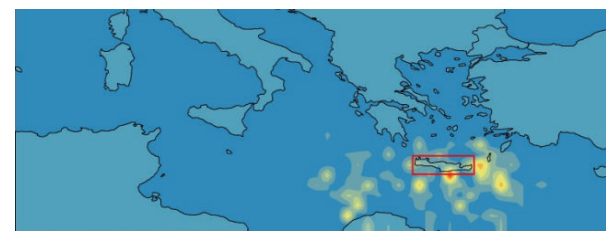

(B3)

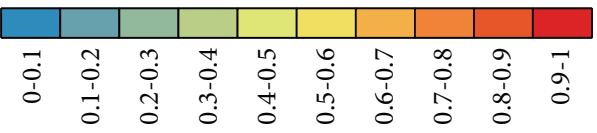

(b)

FIGURE 4: Spatial probability maps (a) and weighted-normalized probability maps (WNP) (b) of "hitting" cyclones for the time period 19792011 for (1) light, (2) medium, and (3) heavy rain events.

values of surface explosive cyclones are found in the southern Ionian Sea and Gulf of Syrte and western Crete (boundaries between the central and eastern Mediterranean).

\subsection{Validation Testing of Probability Maps. The forecasting} potentials of the probability maps are tested with random partition of the dataset in testing and training groups. Probability maps are also validated for specific time periods in which flood events are documented in Crete.

Figure 7 presents the validation results, evaluating the probability maps alone or combined for the three rain categories. The probability thresholds are selected to give the optimal results for the three statistical measures of sensitivity, specificity, and accuracy. For the selected probability thresholds, the mean of all probability map methods for each rain category gives results greater than 0.6 for all three statistical measures. When it comes to choose between sensitivity and specificity optimization, sensitivity is preferred to achieve the optimal values (close to one). This is crucial, especially for medium and heavy rain events, because sensitivity represents cyclones identified to affect Crete during their passage. Medium and heavy rain events are important to be forecasted so as to give a proper alarm for potential flooding.

For light rain events, the selected threshold for the probabilities is 0.3 . Simple probability map "NoCri" achieves the best specificity results $(0.7)$ and the lowest sensitivity results $(0.56)$. On the contrary, "NoCri $+\mathrm{WN}$ " has the lowest specificity $(<0.6)$ and sensitivity reaches 0.8 . The most balanced results are achieved with "WN" and "WN3Cri" in which sensitivity is 0.73 and specificity 0.65 . For these probability maps accuracy is also satisfactory reaching 0.67 .

The results concerning medium rain are obtained for a 0.2 probability threshold, over which cyclones are considered as "affecting." "NoCri" and "3Cri" favor specificity reaching 0.8 and 0.75 correspondingly. "WN" and "WN3Cri" are those considered most satisfactory giving sensitivity results greater than 0.7 and specificity-accuracy beyond 0.6 .

For heavy rain events, the optimal results are obtained for the lowest threshold value (0.1) compared to the other two rain categories. All probability maps give very good results for this threshold. Especially, "3Cri" and "WN3Cri" achieve sensitivity close to 0,8 and specificity-accuracy reaching 0,7 .

Generally, satisfactory results are achieved with "WN" for all rain categories. "NoCri" is the stricter one in sensitivity and favors specificity while "NoCri $+\mathrm{WN}$ " does the exact opposite, favoring sensitivity. "3Cri" relaxes the probabilities giving higher sensitivity results than "NoCri" and the same holds for "WN3cri" compared to "WN".

In addition to testing random partitions of data to validate the probability maps forecasting potentials, certain rain periods that correspond to storms leading to flood events 


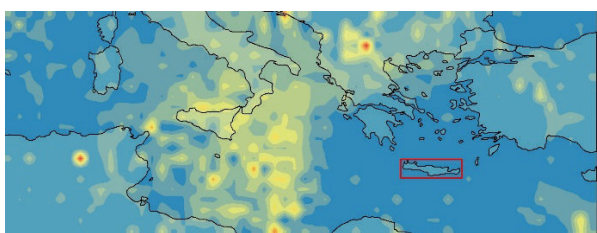

(A1)

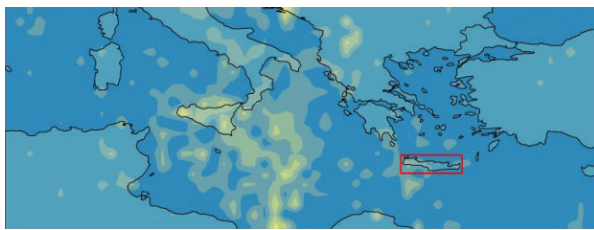

(A2)

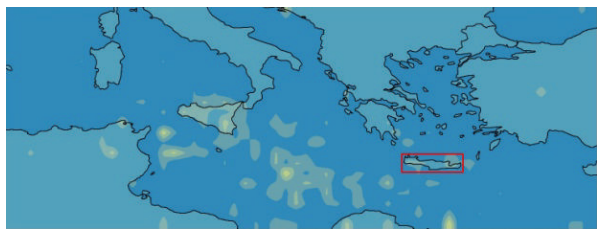

(A3)

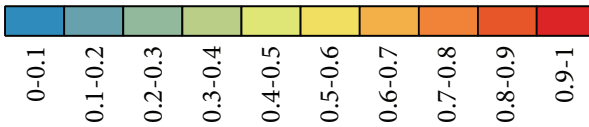

(a)

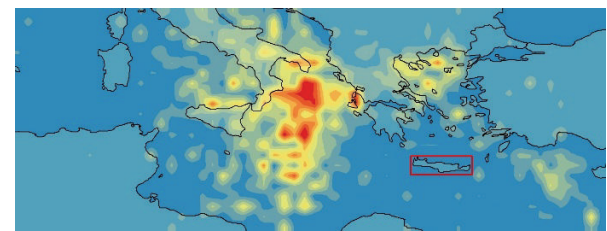

(B1)

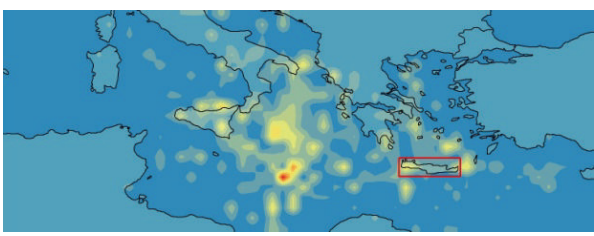

(B2)

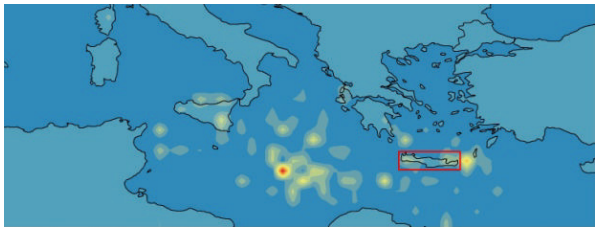

(B3)

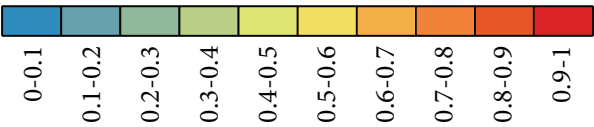

(b)

FIGURE 5: Spatial probability maps (a) and weighted-normalized probability maps (WNP) (b) of "affecting" cyclones for the time period 1979-2011 for (1) light, (2) medium, and (3) heavy rain events.

are also tested and the results are presented in Figure 8. In this case, the preselected rain periods are tested with both the global probability thresholds obtained from the random testing and with the optimal thresholds found for the specific events. In both light and heavy rain the results are better for stricter probability thresholds (thresholds higher than those found in random testing) which is expected because in the selected periods the majority of tracks concern "hitting" cyclones. On the contrary, when data partition is random, tracks concerning rain events are much less so in order to "catch" them the probability thresholds have to be relaxed. The relaxed thresholds in this case have very satisfactory results in sensitivity reaching even 0.8 though specificity hardly reaches 0.6 in a few cases. Only for medium rain the thresholds are found to be identical in both random testing and the specified rain periods.

In more detail, for light rain using the global threshold, sensitivity reaches 0.8 with " 3 Cri" probability map evaluation and sensitivity 0.5 . "3Cri" probability map, using 0.5 as probability threshold, approaches 0.7 in sensitivity and 0.8 in specificity. For medium rain events, good results are obtained with all probability maps combinations. However, "NoCri," "3Cri," and "WN" achieve the optimal balance in the statistical measures of interest. Sensitivity reaches and exceeds 0.8 and specificity ranges between 0.6 and 0.8 . Finally, very satisfactory results in sensitivity are obtained for heavy rain events outreaching 0.8 for both 0.1 and 0.2 probability thresholds. For the global threshold (0.1), specificity ranges between 0.5 and 0.6 while the calibrated threshold (0.2) obtains specificity results reaching 0.8 .

All in all, global probability thresholds give very satisfactory results in sensitivity though the rain period calibrated thresholds improve specificity. Also, "WN" in all cases obtains outstanding results in the statistical measures. Generally, "NoCri" is the most rigorous probability map giving the lowest sensitivity and highest specificity results and "NoCri + WN" is the most relaxed probability map giving the highest sensitivity and lowest specificity results. The rest of the probability maps give results in-between.

\section{Conclusions}

In the present study, we have estimated the probabilities of middle-eastern Mediterranean cyclones to affect Crete with rain of specific daily accumulation for the period 1979-2011. Probability maps of simple and weighted probabilities are estimated for the gridded area of study which are thereafter evaluated for their rain forecasting potentials suggesting an alternative rain diagnostic model.

The detection of the cyclones and their tracks as well as cyclone characteristics such as depth, intensity, and radius, is achieved with the application of MS scheme. Cyclones and rain events recorded in the gauging stations are matched 


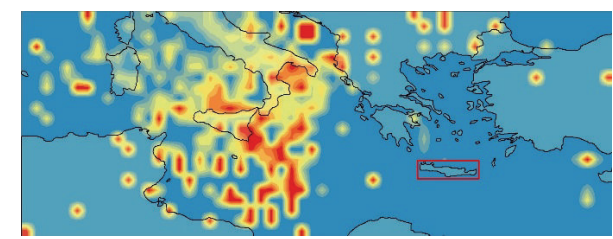

(A1)

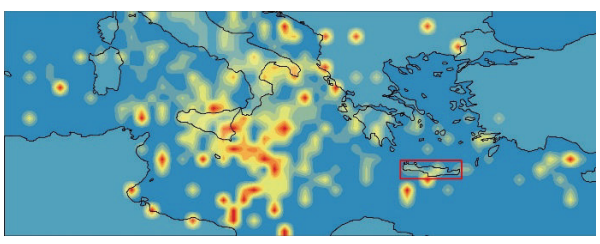

(A2)

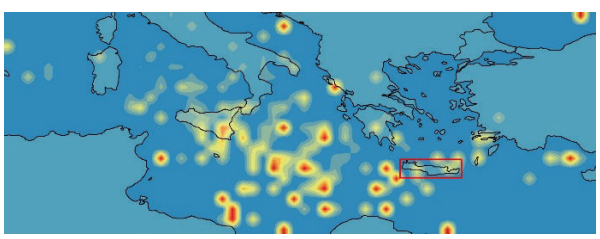

(A3)

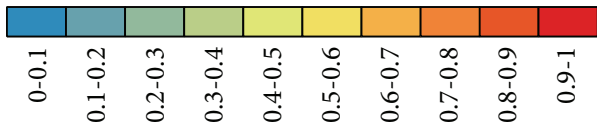

(a)

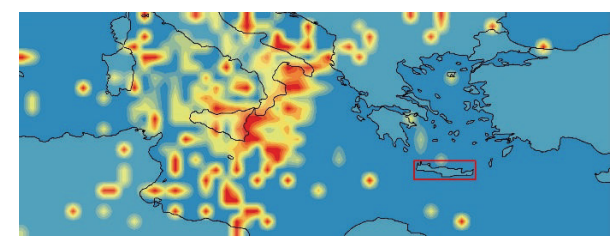

(B1)

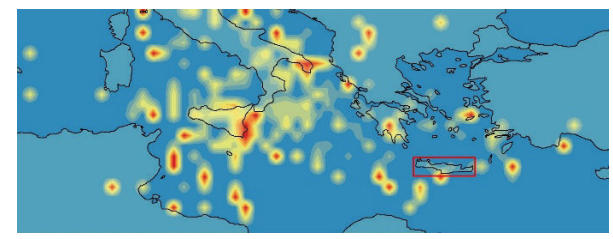

(B2)

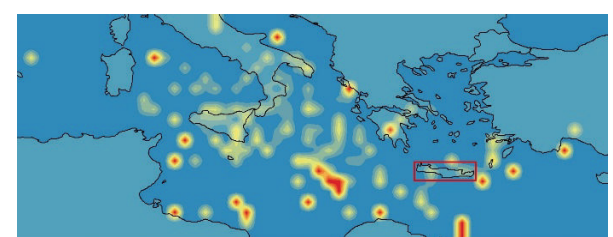

(B3)

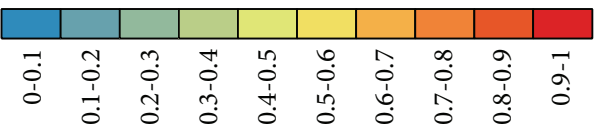

(b)

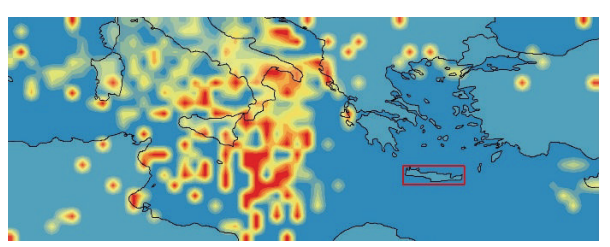

(C1)

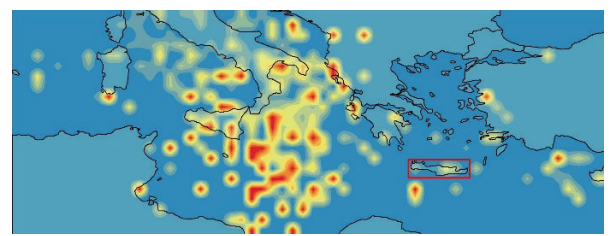

(C2)

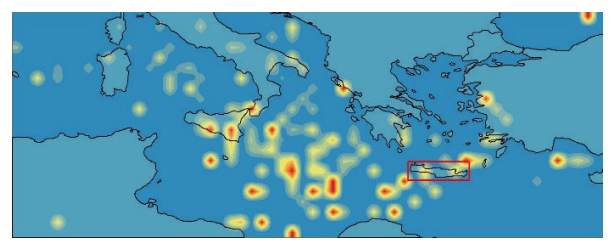

(C3)

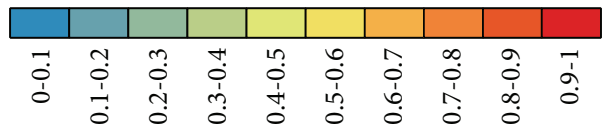

(c)

FIGURE 6: Spatial probability maps of "affecting" cyclones for the time period 1979-2011. The cyclones used are constrained on their (a) depth, (b) radius, and (c) intensity for (1) light, (2) medium, and (3) heavy rain events. 

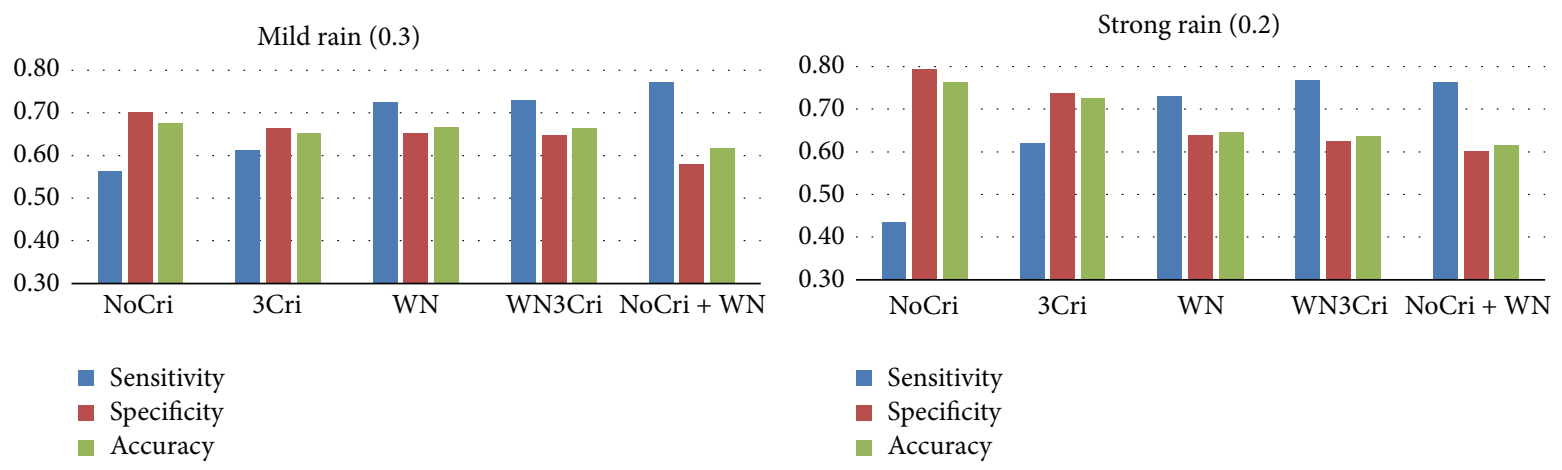

(a)

(b)

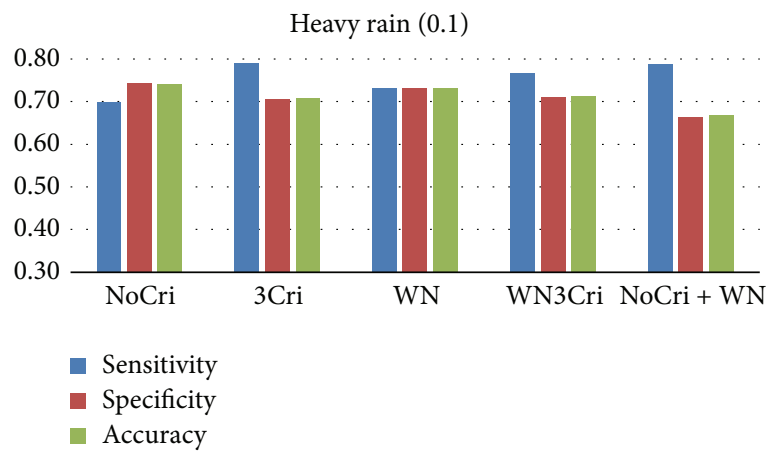

(c)

FiguRE 7: Validation results (sensitivity, specificity, and accuracy) for the probability maps alone and in combinations for the three rain categories. In parentheses are the probability thresholds over which a cyclone is grouped as "affecting."

according to cyclone position relative to Crete. The simple and weighted probabilities of cyclones to affect Crete are then estimated according to the number of affecting cyclones over the total number of cyclones for each grid cell. In order to evaluate the probability maps of affecting cyclones, the cyclone dataset is partitioned in random groups of test and train data and with the use of sensitivity, specificity and accuracy measures are investigated their forecasting potentials. The generalization of the forecast verification of the probability maps is achieved via Monte Carlo simulation (x100) combined with 10 -fold cross-validation obtaining a satisfactory number of independent experiments. The probability maps are also evaluated for recorded cases of wellknown floods in Crete.

The higher probabilities of affecting cyclones are found south of Italy. Generally, greater daily rain accumulations are triggered by cyclones located in southern regions compared to lower daily rain accumulations. With regards to forecasting verification of the probability maps, sensitivity, specificity, and accuracy measures range between 0.6 and 0.8 for the random experiments. Probability maps are estimated using different probability measures on all cyclones or part of them according to the extreme values of their characteristics (radius, depth, and intensity). The probability maps are evaluated alone or in combination giving very efficient results for the tree statistical measures used, in all cases. According to the probability thresholds selected and how strict (high probability threshold) or relaxed (high probability threshold) they are sensitivity, specificity, and accuracy obtain lower or higher scores. The selected probability thresholds over which a cyclone is characterized as affecting optimize the majority of the statistical measures for the different combinations in the probability maps. A statistical measure of great interest is that of sensitivity, especially for heavy rain events, as it identifies rain events giving a warning for potential hazards. The evaluation of specific flood events in Crete also gives promising results reaching in many cases 0.8 in sensitivity and specificity measures.

The scientific community has made a great effort for the study of cyclone climatology [3-5]. Researchers have proved the strong relation between cyclones appearance and precipitation events $[5,13,14]$. In this study, we make one further step, by evaluating the forecasting potential of cyclonic systems alone with the estimation of simple probabilities of rain occurrence. Results could serve as useful-complementary information when combined with other forecasting tools and methods.

\section{Conflict of Interests}

The authors declare that there is no conflict of interests regarding the publication of this paper. 

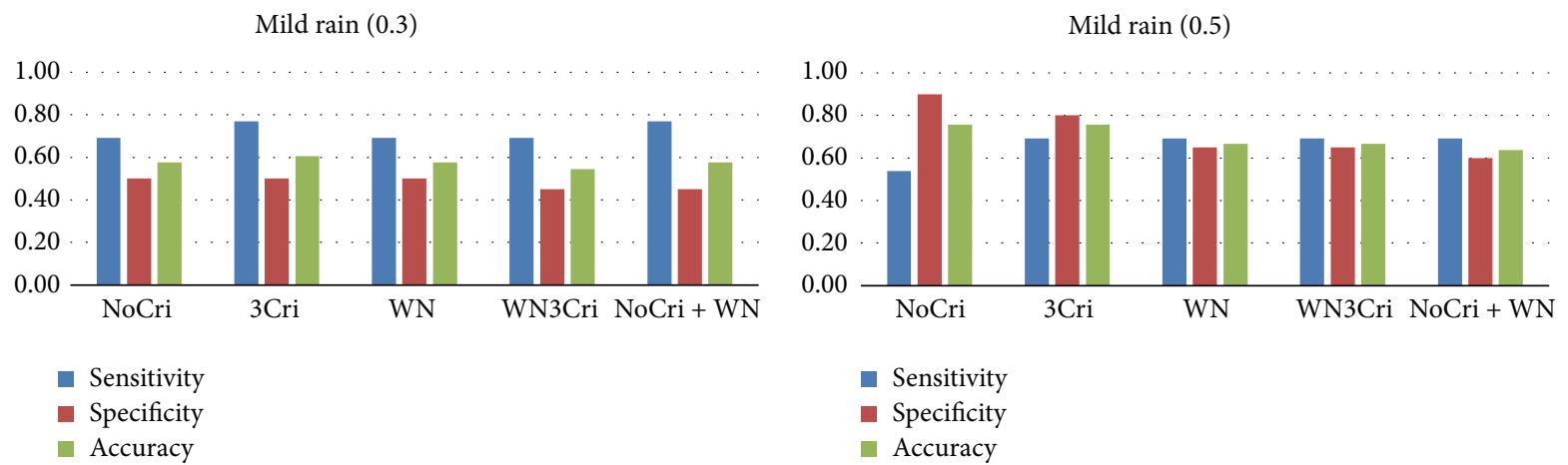

Strong rain $(0.2)$
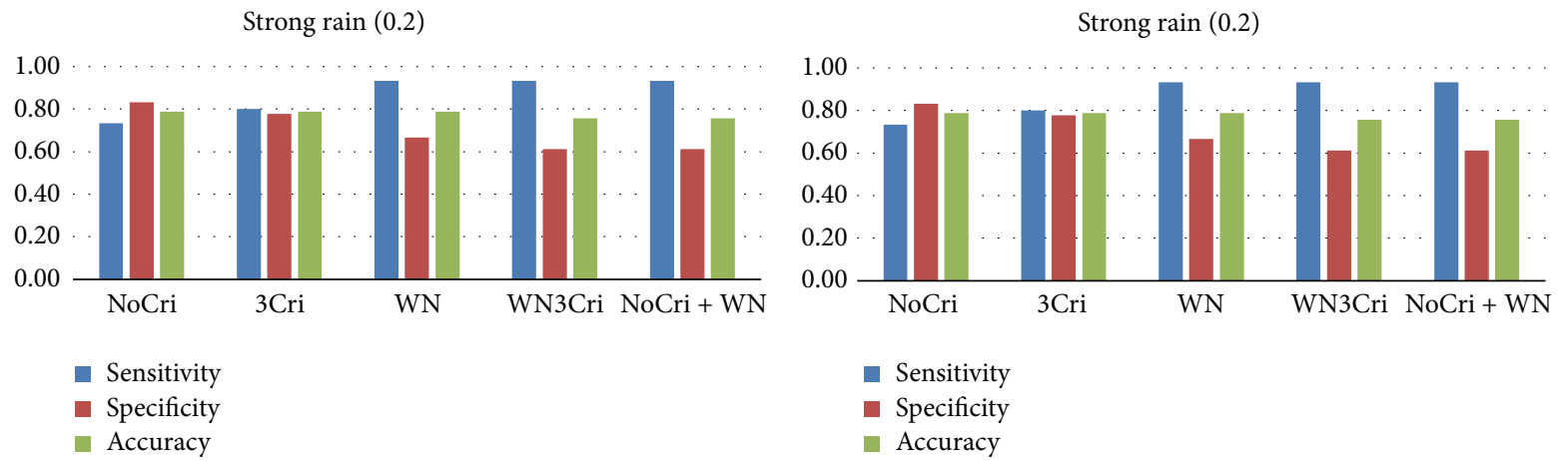

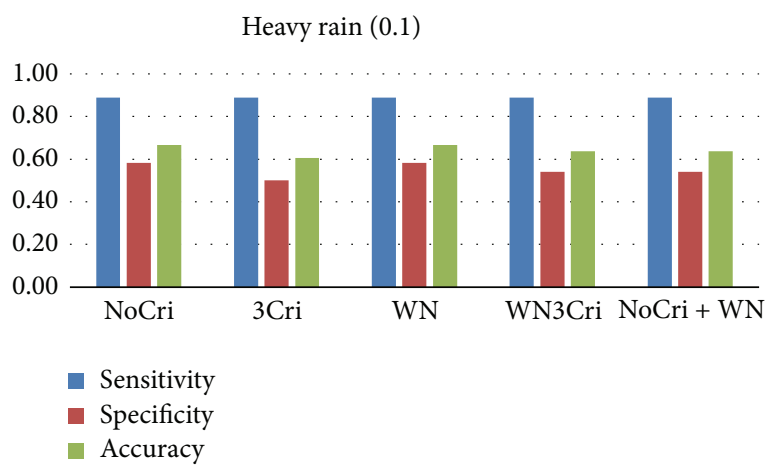

(a)

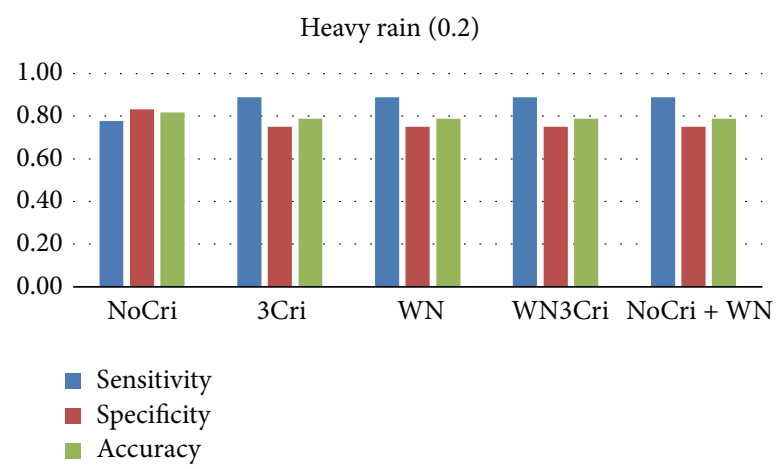

(b)

FIGURE 8: Validation results for specific flood events. The first column is for the probability thresholds (in parenthesis) found to have the best validation results in Figure 7 (global thresholds) and the second column is for the thresholds having the best validation results for the specific flood events.

\section{Acknowledgments}

The authors thank Dr. I. Simmonds from the University of Melbourne who kindly provided the Cyclone Tracking Algorithm. They are grateful to Professor Helena Flocas and the members of her group from the National and Kapodistrian University of Athens for providing valuable guidance through the application process.

\section{References}

[1] A. Jansa, P. Buzzi A, and P. Arbogast, MEDEX, Cyclones That Produce High Impact Weather in the Mediterranean, 2001.
[2] M. Reale and P. Lionello, "Synoptic climatology of winter intense precipitation events along the Mediterranean coasts," Natural Hazards and Earth System Sciences, vol. 13, no. 7, pp. 1707-1722, 2013.

[3] P. Lionello, J. Bhend, A. Buzzi et al., "Chapter 6 cyclones in the Mediterranean region: climatology and effects on the environment," Developments in Earth and Environmental Sciences, vol. 4, pp. 325-372, 2006.

[4] I. F. Trigo, T. D. Davies, and G. R. Bigg, "Objective climatology of cyclones in the Mediterranean region," Journal of Climate, vol. 12 , no. 6, pp. 1685-1696, 1999.

[5] A. Sanna, P. Lionello, and S. Gualdi, "Coupled atmosphere ocean climate model simulations in the Mediterranean region: effect of a high-resolution marine model on cyclones and 
precipitation," Natural Hazards and Earth System Sciences, vol. 13, no. 6, pp. 1567-1577, 2013.

[6] P. Lionello, J. Bhend, A. Buzzi et al., "Chapter 6 cyclones in the Mediterranean region: climatology and effects on the environment," Developments in Earth and Environmental Sciences, pp. 313-358, 2005.

[7] J. Campins, A. Genovés, M. A. Picornell, and A. Jansà, "Climatology of Mediterranean cyclones using the ERA-40 dataset," International Journal of Climatology, vol. 31, no. 11, pp. 15961614, 2011.

[8] M. K. Hawcroft, L. C. Shaffrey, K. I. Hodges, and H. F. Dacre, "How much Northern Hemisphere precipitation is associated with extratropical cyclones?" Geophysical Research Letters, vol. 39, no. 24, Article ID L24809, 2012.

[9] J. L. Catto, C. Jakob, G. Berry, and N. Nicholls, "Relating global precipitation to atmospheric fronts," Geophysical Research Letters, vol. 39, no. 10, Article ID L10805, 2012.

[10] L. Papritz, S. Pfahl, H. Sodemann, H. Wernli, I. Rudeva, and I. Simmonds, "The role of extratropical cyclones andfronts for Southern Ocean freshwater fluxes," Journal of Climate. In press.

[11] A. Jansa, A. Genoves, M. A. Picornell, J. Campins, R. Riosalido, and O. Carretero, "Western Mediterranean cyclones and heavy rain. Part 2: statistical approach," Meteorological Applications, vol. 8, no. 1, pp. 43-56, 2001.

[12] I. F. Trigo, T. D. Davies, and G. R. Bigg, "Decline in Mediterranean rainfall caused by weakening of Mediterranean cyclones," Geophysical Research Letters, vol. 27, no. 18, pp. 29132916, 2000.

[13] P. Maheras, K. Tolika, C. Anagnostopoulou, M. Vafiadis, I. Patrikas, and H. Flocas, "On the relationships between circulation types and changes in rainfall variability in Greece," International Journal of Climatology, vol. 24, no. 13, pp. 16951712, 2004.

[14] P. Lionello and F. Giorgi, "Winter precipitation and cyclones in the Mediterranean region: Future climate scenarios in a regional simulation," Advances in Geosciences, vol. 12, pp. 153-158, 2007.

[15] U. Neu, M. G. Akperov, N. Bellenbaum et al., "Imilast: a community effort to intercompare extratropical cyclone detection and tracking algorithms," Bulletin of the American Meteorological Society, vol. 94, no. 4, pp. 529-547, 2013.

[16] U. Ulbrich, G. C. Leckebusch, J. Grieger et al., "Are Greenhouse Gas Signals of Northern Hemisphere winter extra-tropical cyclone activity dependent on the identification and tracking algorithm?" Meteorologische Zeitschrift, vol. 22, no. 1, pp. 61-68, 2013.

[17] J. Bartholy, R. Pongrácz, and M. Pattantyús-Ábrahám, “Analyzing the genesis, intensity, and tracks of western Mediterranean cyclones," Theoretical and Applied Climatology, vol. 96, no. 1-2, pp. 133-144, 2008.

[18] H. A. Flocas, I. Simmonds, J. Kouroutzoglou et al., "On cyclonic tracks over the Eastern Mediterranean," Journal of Climate, vol. 23, no. 19, pp. 5243-5257, 2010.

[19] H. A. Flocas, P. Maheras, T. S. Karacostas, I. Patrikas, and C. Anagnostopoulou, "A 40-year climatological study of relative vorticity distribution over the Mediterranean," International Journal of Climatology, vol. 21, no. 14, pp. 1759-1778, 2001.

[20] K. Ammar, M. El-Metwally, M. Almazroui, and M. M. A. Wahab, "A climatological analysis of Saharan cyclones," Climate Dynamics.

[21] A. Hannachi, A. Awad, and K. Ammar, "Climatology and classification of Spring Saharan cyclone tracks," Climate Dynamics, vol. 37, no. 3, pp. 473-491, 2011.
[22] K. M. Nissen, G. C. Leckebusch, J. G. Pinto, D. Renggli, S. Ulbrich, and U. Ulbrich, "Cyclones causing wind storms in the Mediterranean: characteristics, trends and links to large-scale patterns," Natural Hazards and Earth System Science, vol. 10, no. 7, pp. 1379-1391, 2010.

[23] I. Rudeva and S. K. Gulev, "Climatology of cyclone size characteristics and their changes during the cyclone life cycle," Monthly Weather Review, vol. 135, no. 7, pp. 2568-2587, 2007.

[24] I. Simmonds, "Size changes over the life of sea level cyclones in the NCEP reanalysis," Monthly Weather Review, vol. 128, no. 12, pp. 4118-4125, 2000.

[25] J. L. Mcbride and E. E. Ebert, "Verification of quantitative precipitation forecasts from operational numerical weather prediction models over Australia," Weather and Forecasting, vol. 15, no. 1, pp. 103-121, 2000.

[26] M. Vich, R. Romero, and V. Homar, "Ensemble prediction of Mediterranean high-impact events using potential vorticity perturbations. Part II: adjoint-derived sensitivity zones," Atmospheric Research, vol. 102, no. 3, pp. 311-319, 2011.

[27] A. G. Koutroulis, I. K. Tsanis, and I. N. Daliakopoulos, "Seasonality of floods and their hydrometeorologic characteristics in the island of Crete," Journal of Hydrology, vol. 394, no. 1-2, pp. 90-100, 2010.

[28] A. G. Koutroulis, M. G. Grillakis, I. K. Tsanis, V. Kotroni, and K. Lagouvardos, "Lightning activity, rainfall and flash floodingoccasional or interrelated events? A case study in the island of Crete," Natural Hazards and Earth System Science, vol. 12, no. 4, pp. 881-891, 2012.

[29] A. Mouratidis, G. Doxani, M. Nikolaidou, M. Lampiri, F. Sarti, and M. Tsakiri-Strati, "Contribution of geographical informationsystems and earth observation data to mapping and managing flood events in Greece," International Journal of Geographical Information Science. In press.

[30] R. J. Murray and I. Simmonds, "A numerical scheme for tracking cyclone centres from digital data. Part I: development and operation of the scheme," Australian Meteorological Magazine, vol. 39, no. 3, pp. 155-166, 1991.

[31] R. J. Murray and I. Simmonds, "A numerical scheme for tracking cyclone centres from digital data. Part I: development and operation of the scheme," Australian Meteorological Magazine, vol. 39, no. 3, pp. 155-166, 1991.

[32] P. Hope, K. Keay, M. Pook et al., "A comparison of automated methods of front recognition for climate studies: a case study in Southwest Western Australia," Monthly Weather Review, vol. 142, pp. 343-363, 2014.

[33] E.-P. Lim and I. Simmonds, "Southern hemisphere winter extratropical cyclone characteristics and vertical organization observed with the ERA-40 data in 1979-2001," Journal of Climate, vol. 20, no. 11, pp. 2675-2690, 2007.

[34] I. Simmonds and K. Keay, "Mean southern hemisphere extratropical cyclone behavior in the 40-year NCEP-NCAR reanalysis," Journal of Climate, vol. 13, no. 5, pp. 873-885, 2000.

[35] J. Kouroutzoglou, H. A. Flocas, K. Keay, I. Simmonds, and M. Hatzaki, "Climatological aspects of explosive cyclones in the Mediterranean," International Journal of Climatology, vol. 31, no. 12, pp. 1785-1802, 2011.

[36] J. Kouroutzoglou, H. A. Flocas, K. Keay, I. Simmonds, and M. Hatzaki, "On the vertical structure of Mediterranean explosive cyclones," Theoretical and Applied Climatology, vol. 110, no. 1-2, pp. 155-176, 2012. 

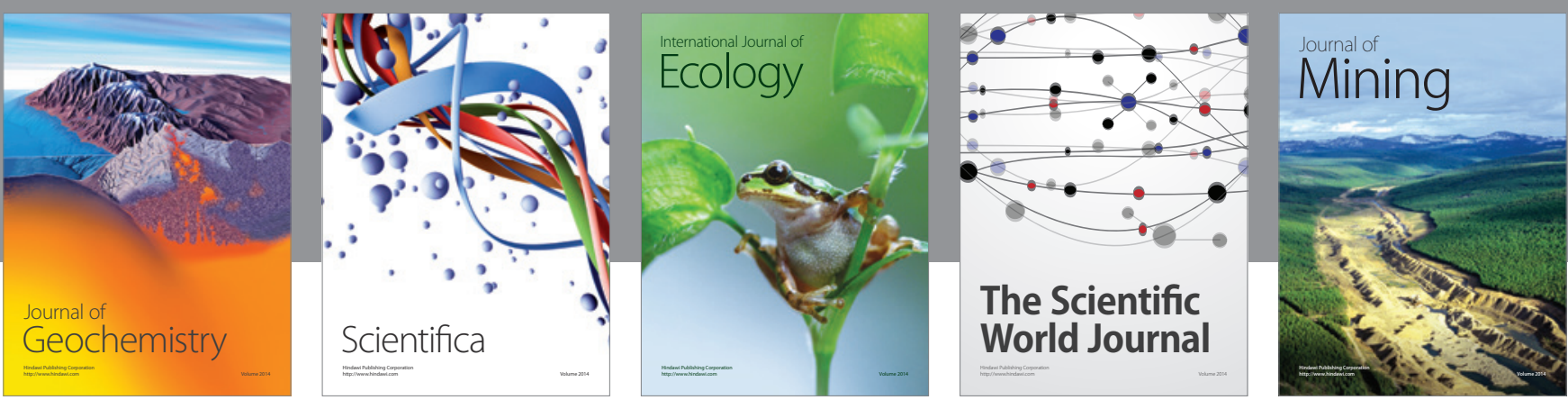

The Scientific World Journal
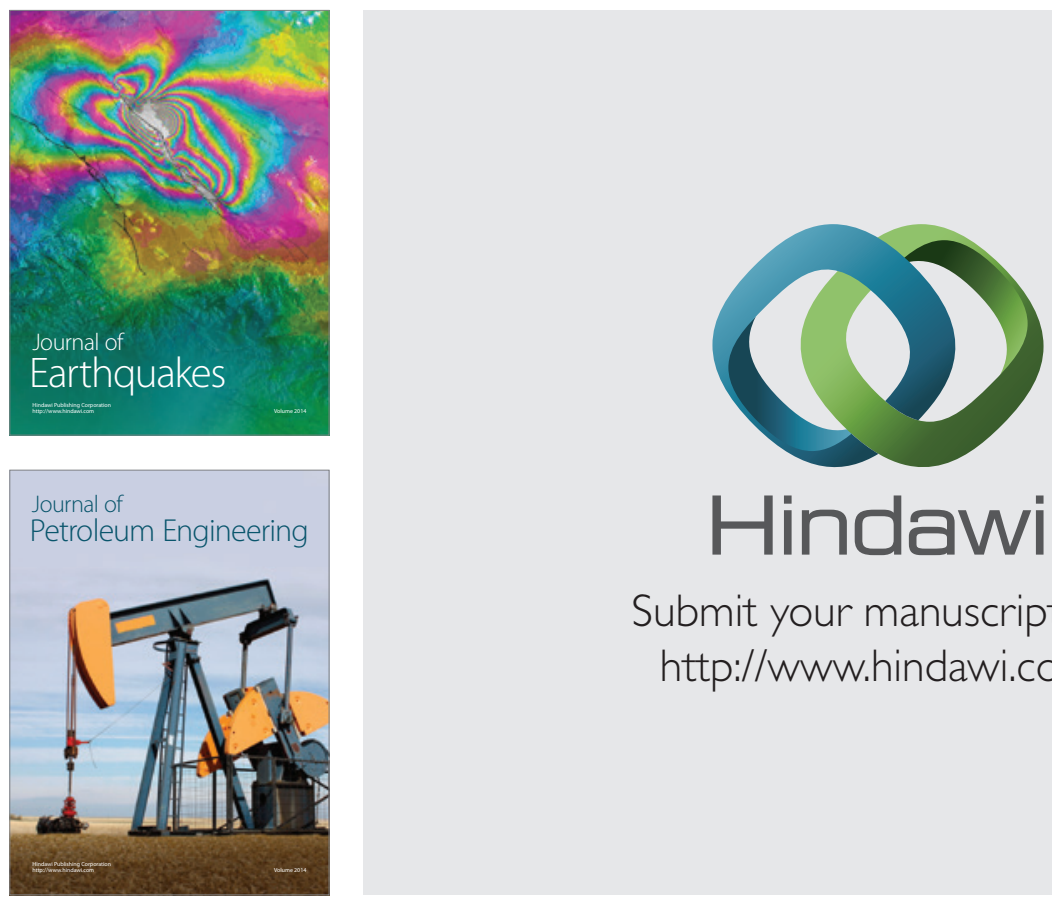

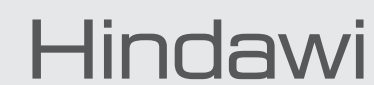

Submit your manuscripts at

http://www.hindawi.com
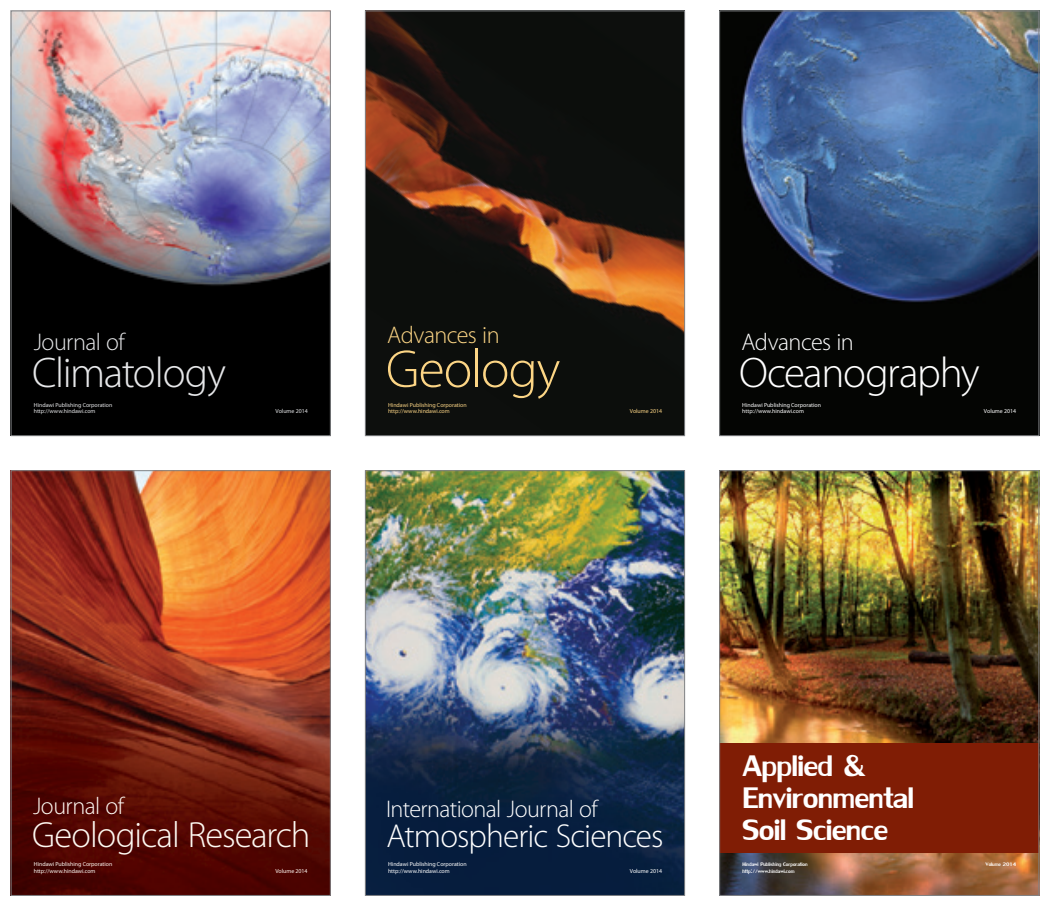
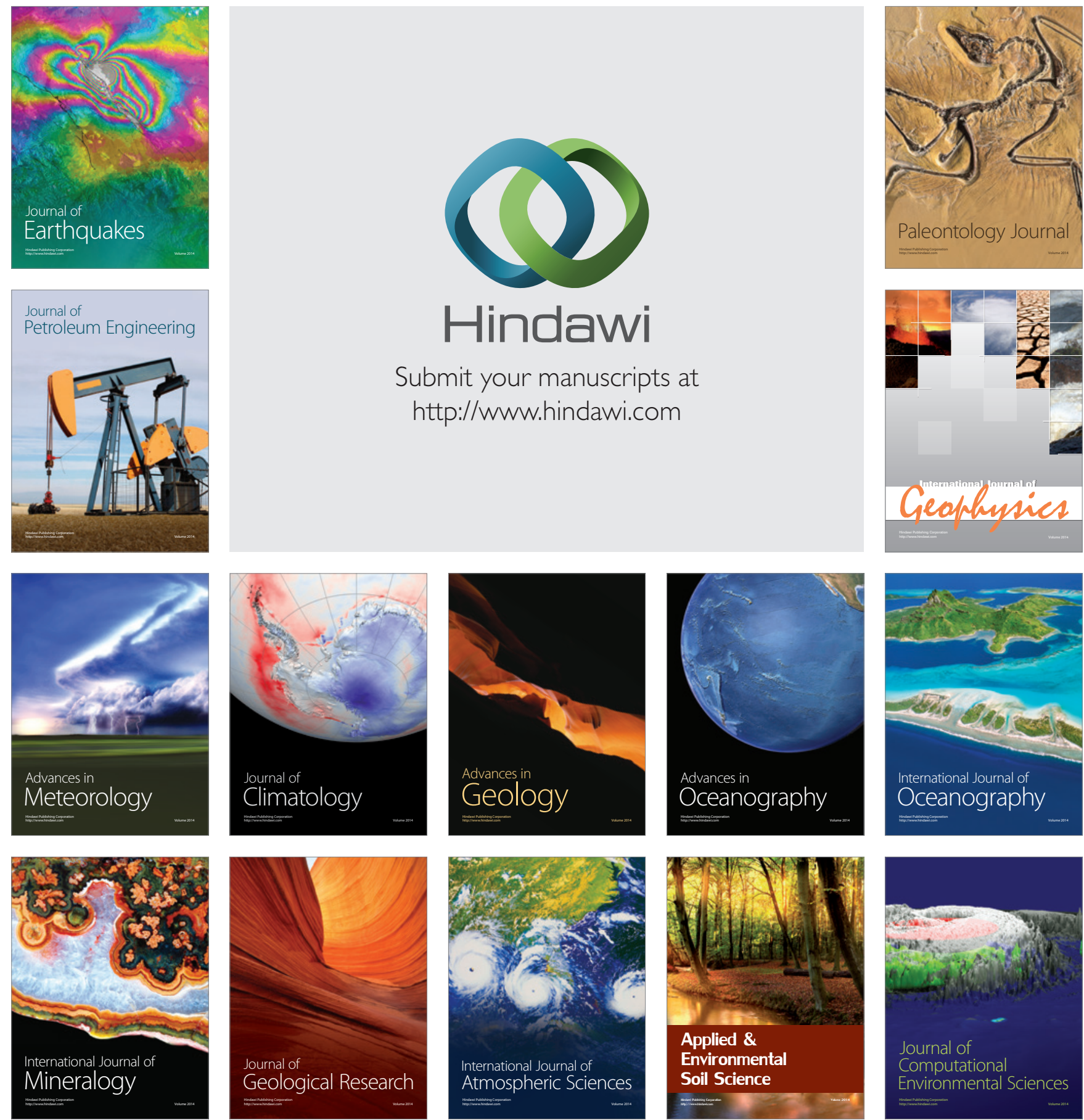